Full length article

\title{
In the ovary of Ciona intestinalis (Type A), immune-related galectin and phenoloxidase genes are differentially expressed by the follicle accessory cells
}

\author{
Daniela Parrinello ${ }^{\mathrm{a}}$, Maria Antonietta Sanfratello ${ }^{\mathrm{a}}$, Maria Giovanna Parisi ${ }^{\mathrm{a}}$, Aiti Vizzini ${ }^{\mathrm{b}}$, \\ Matteo Cammarata ${ }^{\text {a,* }}$
}

a Dipartimento di Scienze della Terra e del Mare, Viale delle Scienze Ed. 16, Palermo, Italy

b Dipartimento di Scienze e Tecnologie Biologiche, Chimiche e Farmaceutiche, Via Archirafi 18, Palermo, Italy

\section{A R T I C L E I N F O}

\section{Keywords:}

Accessory cells

Ovary

Ciona intestinalis

Galectins

Phenoloxidase

\begin{abstract}
A B S T R A C T
Riboprobes (in situ hybridization) and antibodies (immunohistochemistry), previously used to show the upregulation of Ciona intestinalis (Type A) galectins (CiLgals-a, CiLgals-b) and phenoloxidase (CinPO2) immunerelated genes, were tested on histological sections of the ovary. The ovarian follicles are composed of oocytes encased by follicular cells (FCs) and test cells (TCs). Results show the transcription upregulation of both CiLgals and CinPO2 genes in the vitellogenic FCs, conversely distinct cytolocalization of the proteins are shown. At vitellogenic stage, the CiLgals are localized in the FCs, in the oocyte cytoplasm, and close to the germinal vesicle (GV), whereas the CinPO2 was never identified in the FCs. In a presumptive advanced phase and at the postvitellogenic stage the TCs appear to be labelled by the CinPO2 riboprobe, and the protein identified by the antibody suggesting an mRNA transcytosis process from FCs. At post-vitellogenic stage the CiLgals mainly enrich the GV nucleoplasm, whereas the CinPO2 is contained in TCs and in the ooplasm but never found in the GV. This finding sheds new light on a former paper in which TCs were reported to be the only CinPO2-producing cells in the ovarian follicle. Finally, CiLgals and CinPO2 genes transcription and proteins production seem to be associated with accessory cells during their differentiation from vitellogenic to post-vitellogenic stage. The present findings promote further research on the early upregulation of immune-related genes, and the potential multifunctional role of the produced proteins. In addition further insight on the accessory cells involvement in ascidian oogenesis are reported.
\end{abstract}

\section{Introduction}

Tunicata a chordate subphylum, which includes the ascidians, are retained the sister group of vertebrates [1,2], and most of them are hermaphroditic. In the ascidians Boltenia villosa and Ciona intestinalis, the expression of several immune-related vertebrate homologs genes (mannose specific lectin, hemocytin, complement factors, selectins, pentraxin and von Willibrand factors) have been reported in embryos, during the brief larval phase, and metamorphosis [3-6]. In Ciona intestinalis (Type A), a CiTNF $\alpha$-like gene is expressed in swimming larvae [7], while the transcription of a phenoloxidase gene (CinPO2) is modulated in embryogenesis and larva stages [8]. In addition, a homolog of the CD94 (CiCD94) vertebrate receptor of NK cells, is expressed during larva development [9].

In ascidians, maternally provided mRNAs and proteins drive the early embryogenesis and activate the zygotic genome [10-14]. Many developmental biology and gene expression protocols, including whole mount in situ hybridization assay, require removal of the accessory cells [15-17]. However, this removal can subtly alter the development of embryos and larva metamorphosis [18-20]. In C. intestinalis (Type B), dechorionated growth alters cell organization in the embryonic ectoderm pattering [21]. Therefore, it is of interest to examine the relationship between the accessory cells and the oocyte that may begin in the growing follicle.

Galectins are components of a lectin family of extensive taxonomic distribution and striking evolutionary conservation, characterized by a conserved carbohydrate recognition domain (CRD) with a relatively high affinity to $\beta$-galactosides $[22,23]$. They are involved in immunity, cell communication, self not-self recognition, cell proliferation, development, differentiation and malignant transformation [22-25]. Intracellular galectins participate in a wide variety of biological phenomena, and a single galectin can exert multiple roles [25,26,27].

\footnotetext{
* Corresponding author. Marine Immunobiology laboratory Dept. DISTEM, Italy.

E-mail address: matteo.cammarata@unipa.it (M. Cammarata).
} 
Several galectins have been found in invertebrate species, including ascidians and cephalochordates [23,28,29,30]. In C. intestinalis (Type A), two bi-CRD galectins (CiLgals-a and CiLgals-b) have been identified and some their structural features examined $[29,30,31]$. In fish, they have a role in fertilization and are differentially expressed during early development $[35,36]$.

The "prophenoloxidase (proPO) activating system" is a component of the invertebrate innate immunity. Upon activation by $\beta-1,3$ glucans or LPS, a limited proteolysis (serine proteases) of the proenzyme produces the active phenoloxidase (PO). Intermediate pathway products (quinones or oxygen radicals) can exert cytotoxic activity [37-39]. A C. intestinalis PO (CinPO2) has been cloned and sequenced [40,41]. This enzyme appears to be involved in development [8].

It is generally accepted that transcript and protein localization in distinct tissues and cells are indicative of tissue functions. Thus, we examined the inflammatory response to LPS of the $C$. intestinalis pharynx, which has been defined the main immune competent organ [42], and transcription upregulation of the CiLgals and CinPO2 genes have been shown [31,43]. In situ hybridization and immunohistochemistry assays revealed that the constitutive expression of CiLgals can be enhanced in pharynx vessel epithelium, hemocytes and endostyle $[31,44]$, as well as an increased CinPO2 expression was found in hemocytes that populate the tunic matrix [43].

In $C$. intestinalis, the male and female gonads are located in the major mesenchymal space of the adult, situated in the abdomen [45]. The ovary consists of a branched ovarian tube and follicles formed by growing oocytes encased by their accessory cells [46]. The ovary follicles are usually distinguished in three stages: young oocyte of smaller size in which the accessory cells layers may be incomplete (stage I); vitellogenic (stage II) and post-vitellogenic (stage III) follicles which are formed by the oocyte-accessory cells complex [47-49]. According to a transmission electron microscopy study by Mancuso [48], the C. intestinalis (type A) ovarian follicles at vitellogenic and post-vitellogenic stages are composed of two maternal accessory cell types which surround the oocytes: follicle cells (outer layer, FCs), and test cells (inner layer, TCs) which are in contact with the oocyte membrane. A thin acellular vitelline coat (VC) connects FCs and TCs $[48,50]$. In the growing follicle, the TCs become embedded in the outermost cytoplasm of the oocyte and form a dense layer [48,51]. The nucleus (germinal vesicle, GV) of the oocytes is arrested at first meiotic prophase and it is provided with one nucleolus. The mature follicles (stage IV, post-GV break down, GVBD), contained in the oviduct, show long spike-shaped and vacuolated FCs, while the TCs are released into the perivitelline space $[48,51]$. The follicle growth is regulated by endogenous factors, including a tachikinin-like peptide (CiTK) and its receptor (CiTK-R) [52].

In this paper, the expression of innate immune-related genes (CiLgals and CinPO2) in the ovary of C. intestinalis is reported, and histological observations shed further light on the activity of the follicle complex: transcripts have been found in accessory cells, meanwhile the proteins are differently localized in these cells and in growing oocytes. We tested the riboprobes (in situ hybridization with CiLgals-a, CiLgals-b and $\mathrm{CinPO} 2$ probes) and the antibodies (immunohistochemistry with anti-CiLgals-a or CiLgals-b antibody, and anti-CinPO2 antibody) that are known to be specific to their targets during the inflammatory response $[8,31,44]$. Although the functions of CiLgals and CinPO2 in follicles can only be hypothesized, our findings provide insights for further research on the involvement of the accessory cells during the follicle growing phases, while they suggest a potential multifunctional role of the immune-related genes in distinct phases of the ascidian life cycle.

\section{Material and methods}

\subsection{Animals}

Recently, at least two species, temporarily named $C$. intestinalis type A and B, with different geographical distribution, have been proposed $[53,54]$. The type A has also been designate as C. robusta [55] geographically distributed in the Mediterranean, Pacific, and Southern Atlantic coasts of Europe [54,56]. Nonetheless, evidence of incomplete reproductive isolation from the wild population within the shared range of A and B types, raises the taxonomic issue [57]. Based on the collection sites, most published reports on the oocytes and accessory cells derive from Type A animals $[46,50,51,58,59]$, in addition, all our studies have been performed on specimens from the Mediterranean coasts. Therefore, waiting for the taxonomic status to be precisely defined, in the present paper the name $C$. intestinalis (Type A) is kept.

Adult ascidians were gathered from Termini Imerese (Sicily, Italy) marinas during the springtime, maintained in tanks with aerated seawater at $15{ }^{\circ} \mathrm{C}$, under constant light, and fed every second day with a marine invertebrate diet (Coraliquid, Sera Heinsberg, Germany). The ovary was removed from the outer surface of intestinal loop. The study was performed in full compliance with the national (D.Lgs n.116/1992 and n.26/2014) and international European Commission Recommendation guidelines for the accommodation and care of animals used for experimental and other scientific purposes (2007/526/ EC).

\subsection{Histological methods, antibody specificity, immunohistochemistry (IH)} and in situ hybridization (ISH) assays

The antibodies and the riboprobes were the same that specifically recognized the two galectins and the CinPO2 expressed by the inflamed pharynx $[8,31]$. IH with selectively purified antibodies (provided by GenScript USA Inc.) was performed. The titer $(1: 25,000)$ of the antibody preparations, and specificity were tested by ELISA on plates (Nunc, Denmark) coated with the peptide (10 $\mu \mathrm{g} /$ well) used as an antigen. The coated plates treated with antibody preparations (1:1000$1: 50,000)$, or pre-immune rabbit serum (1:50-1:200), in blocking solution, were incubated with peroxidase-conjugated anti-rabbit IgGs $(1: 10,000)$, and then with $o$-phenylenediamine. The peroxidase product was quantified at $492 \mathrm{~nm}$. The antibody specificity was further shown by competitive peptide ELISA as formerly reported in detail [60]. Antirabbit IgG phosphatase alkaline conjugated antibody was used as secondary antibody (1:10,000; $90 \mathrm{~min}$ at r.t.). Sections only treated with the secondary antibody or pre-immune serum (not shown) were as a control. The rinsed sections were stained with BCIP/NBT liquid substrate system.

The ISH was performed with the CiLgals-a, CiLgals-b or CinPO2 digoxigenin-11-UTP-labeled antisense probes $(1 \mathrm{mg} / \mathrm{ml}$ final concentration) (Roche Diagnostics) as formerly reported in details [8,31]. According to the former papers, the incubation of histological sections with the anti-sense probes at $37{ }^{\circ} \mathrm{C}$, allowed us to obtain cleaner controls. The treatment with sense probe preparations was as a control.

Ovary serial sections were prepared and alternatively treated with immunohistochemistry or in situ hybridization probes, and examined under a Leica DMRE microscope. Mallory's trichrome stain [61] was used to point out the histological organization of the oocytes.

\section{Results}

\subsection{Mallory's staining of ovary sections}

Fig. 1A shows a general view of the ovary, and Fig. 1A-C shows follicles in which the oocytes are encased in the accessory cells (FCs and TCs) layers. Stage I (pre-vitellogenic), stage II (vitellogenic) and stage III (post-vitellogenic) were distinguished on the basis of their size and 

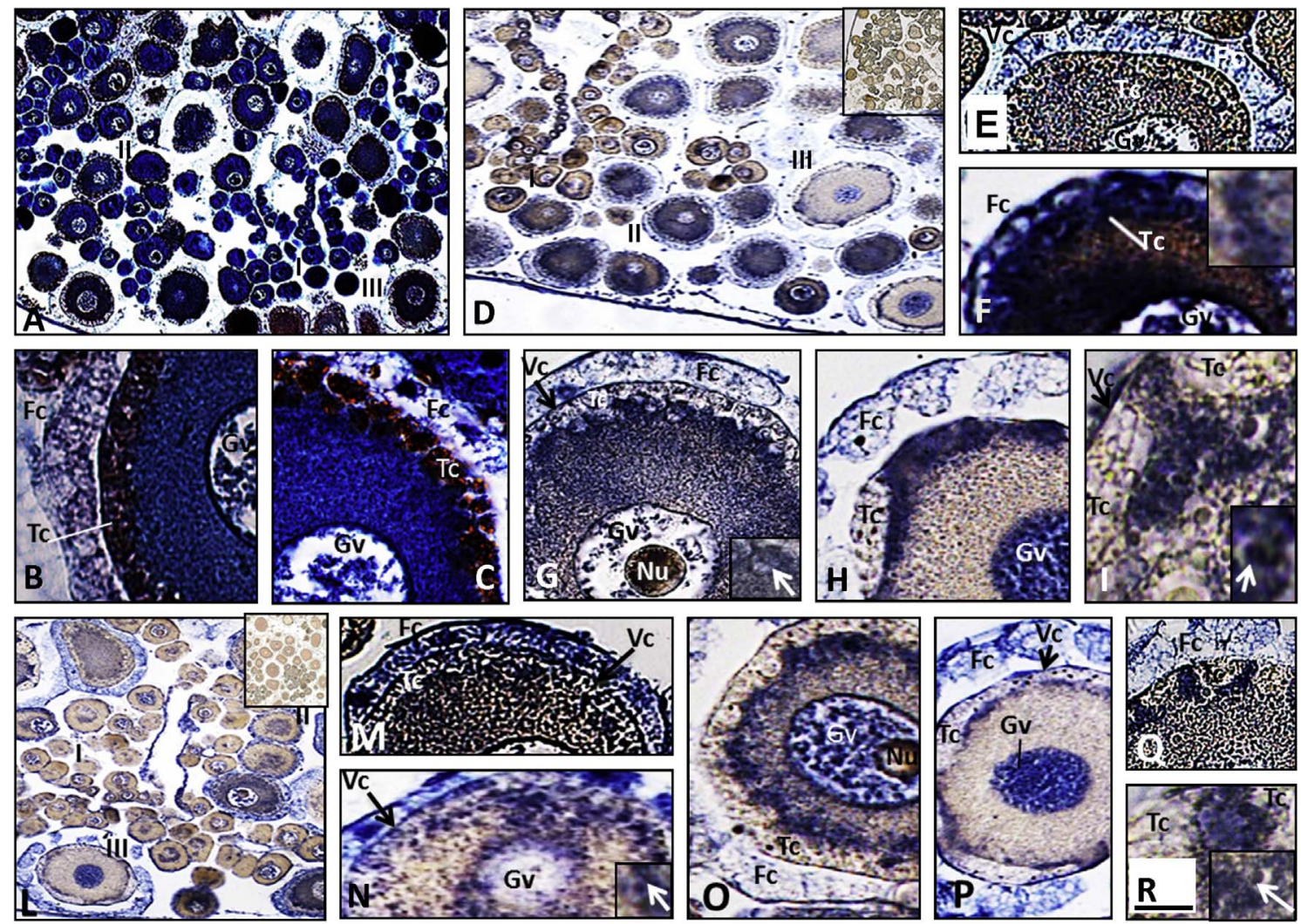

Fig. 1. Histological sections of Ciona intestinalis ovary. Mallory's staining and immunohistochemistry (anti-CiLgals-a or anti-CiLgals-b primary antibody).

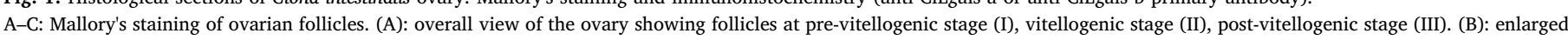

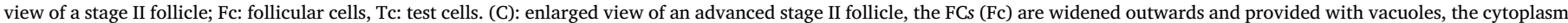

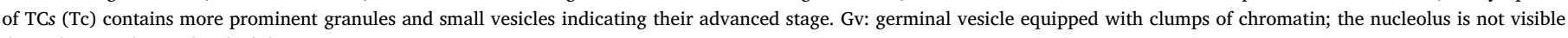
depending on the cut level of the section.

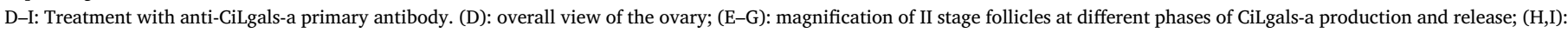

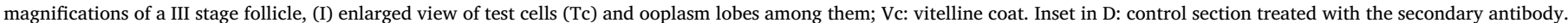

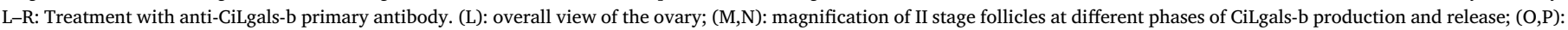
magnifications of a III stage follicle; $(\mathrm{Q}, \mathrm{R})$, test cells and ooplasm lobes between them. Inset in L: control section treated with the secondary antibody.

The bar, shown in the figure R, also applies to all the others, and the relative measures are as follows: $100 \mu \mathrm{m} \mathrm{in} \mathrm{A}, \mathrm{D}, \mathrm{L} ; 20 \mu \mathrm{m}$ in I, R; $10 \mu \mathrm{m}$ in B, C, E, F, G, H, M, N, O, P, Q.

accessory cells features. The accessory cell morphology was related to the follicle growth phases, and they appeared to be contemporaneously modified during the oogenesis. At stage I ( $<50 \mu \mathrm{m}$ in diameter), undifferentiated primary FCs were only occasionally visible or incompletely covering the oocyte (not shown). At stage II $(50-70 \mu \mathrm{m}$ in diameter), oocytes containing abundant cytoplasm, were enveloped by prominently individualized fibroblast-shaped or cube-shaped FCs in contact each other to form a continuous layer, meanwhile TCs appeared encased in superficial depressions of the oocyte (Fig. 1B). At that stage, the cytoplasm of FCs was characterized by transparent vacuoles varying in size and shape, and the cytoplasm of TCs contained small vacuoles and granules (Fig. 1B). Fig. 1C shows the accessory cells of an advanced stage II follicle in which FCs contained larger vacuoles, while the TCs were filled with granules. Stage III follicles (about $100 \mu \mathrm{m}$ in diameter) are visible in Fig. 1A, they present a more outstanding feature of the FCs, which were widened outwards and provided with large vacuoles, while numerous prominent granules occupied the cytoplasm of TCs. The examined histological sections did not allow to distinguish two FC layers (inner and outer), as well as stage IV follicles were never found. A large GV characterized the oocytes (Fig. 1B,C).

\subsection{IH with anti-CiLgals antibodies and ISH with CiLgals riboprobes}

The immunoreactivity with the anti-CiLgals-a (Fig. 1D-I) or -b (Fig. 1L-R) antibody was mainly detected in stage II and III follicles, and both galectins presented a similar distribution. Fig. 1 shows different phases of CiLgals localization. In stage II follicles, the FC layer was well-marked by both antibodies (Fig. 1E-G,M,N), whereas the TC layer, at the periphery of the ooplasm, was unmarked (Fig. 1E,G,M). In other histological sections, the ooplasm periphery appeared to be enriched with vesicles containing positive granules that mask the TC layer (Fig. $1 \mathrm{~F}$ and inset), while similar positive vesicles were observed just below this layer (Fig. 1F,N and insets). In a presumptive advanced stage II, the immunoreaction with both antibodies showed the ooplasm containing positive material, mainly inside vesicles varying in size, that were close to the TC layer (Fig. 1F,G,N). Fig. 1G also shows that the TCs no longer had the ability to bind the antibody. This feature was more evident in follicles at the subsequent stage III. Furthermore, more or less intense immunoreaction was scattered in the ooplasm to form a decreasing gradient from the periphery to the nucleus where it marked the GV outer surface (Fig. 1F,G,N). Inside the GVs a loose positive granular content could be seen (Fig. 1F,G,N).

In stage III follicles, the antibodies feebly marked the vacuolated and outstanding FCs, meanwhile the unmarked TCs appeared to be vacuolated and rich in granules (Fig. 1H,I,O,P,Q,R). The immunoreactivity with both antibodies was mostly restricted to ooplasmic lobes that occupied the intercellular spaces between the unreactive TCs (Fig. 1H,I,Q,R). The imunoreaction products could be contained inside vesicles (Fig. 1I,R and insets). In the GV, the antibodies marked granules that occupied the entire nucleoplasm area (Fig. 1D,H,L,P).

Finally, immunoreactive material was found to be associated to the VC layer interposed between the FC and TC layers of follicles at II and 

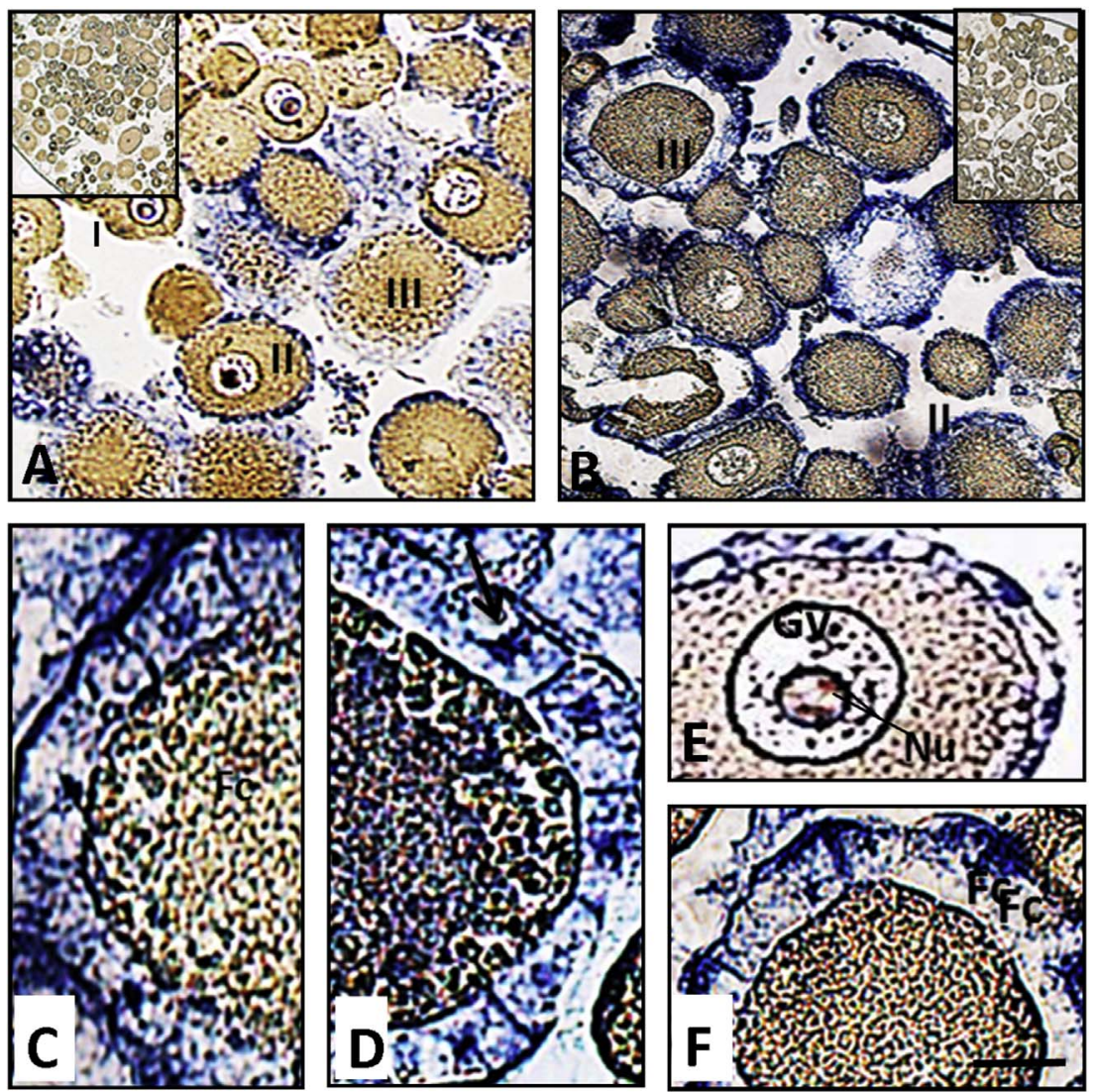

Fig. 2. Histological sections of Ciona intestinalis ovary. In situ hybridization with CiLgals-a or CiLgals-b riboprobe.

(A): overall view of the ovary treated with CiLgals-a riboprobe; (B): ovary section treated with CiLgals-b riboprobe; (C,D): larger views of ovarian follicles treated with CiLgals-a riboprobe (C), or CiLgals-b riboprobe (D). (E): germinal vesicle (Gv) and nucleolus (Nu) unmarked by the CiLgals-a riboprobe, the same result was found with the CiLgals-b riboprobe (not shown). (Y): follicular cells in a follicle before reaching the stage III. Insets in A and B: control sections treated with the CiLgals-a or CiLgals-b sense strands, respectively. The bar, shown in the figure F, also applies to all the others, and the relative measures are as follows: $100 \mu \mathrm{m}$ in $\mathrm{A}, \mathrm{B} ; 17 \mu \mathrm{m}$ in E; $10 \mu \mathrm{m}$ in C, D, F.
III stages (Fig. 1E,I,M,N,P,Q).

In serial histological sections, in situ hybridization assays showed that both CiLgals-a and CiLgals-b riboprobes labeled the FCs that enveloped the stage II oocytes (Fig. 2A-F). The central area of the FCs, where presumably the nucleus was located, was labeled by the riboprobes (Fig. 2C and D). The FCs of stage III follicles were variously labeled by both riboprobes (Fig. 2A-F). In both oocyte stages, none of the used probes brands the GVs and the ooplasm (Fig. 2A,B,E), whereas riboprobes label some VC traits (Fig. 2C-F).

Controls with the secondary antibody and sense riboprobes are shown by the insets of Fig. 1D and Fig. 2 A,B, respectively.

3.3. CinPO2 gene transcription occurs in FCs, while TCs are involved in the production of the enzyme

Fig. 3A and B shows that FCs of stage II follicles were labeled by the CinPO2 riboprobe, whereas the TCs were unlabeled (Fig. 3A). In Fig. 3F, the control with the sense probe is shown. By comparing Fig. 3A and Fig. 3C,D,E, the riboprobe, formerly absent in TCs shown by Fig. 3A, labeled both FCs and TCs shown by Fig. 3C,D,E, and the plenty of marking could obfuscate the TCs morphology (Fig. 3D). In particular, Fig. 3E shows riboprobe label in the accessory cells as well as in VC layer. The GV was never marked by the riboprobe (Fig. 3C,E).

The immunohistochemistry with anti-CinPO2 antibody did not recognize CinPO2 in the FCs of stage II follicle, and it was never contained in their cytoplasm, as clearly shown by Fig. 3G-L. Conversely, the immunoreactive material marks the TCs (Fig. 3G-I) and it was contained in vesicles associated to the TC layer and spreaded into the surrounding ooplasm (Fig. $3 \mathrm{H}$ and I). The insert in Fig. 3G shows that vesicles containing the enzyme can be manufactured by the TCs. In a more advanced II stage, the TCs were feebly marked (Fig. 3L), while the ooplasm was enriched with positive vesicles (Fig. 3N). In stage III follicle, the TCs were rich in unmarked granules, while positive ooplasm lobes were inserted between the TCs (Fig. 3M). In these ooplasm lobes, vesicles containing the CinPO2 could be distinguished (Fig. $3 \mathrm{~N}$ ). The GVs were never marked by the antibody (Fig. 3H-M). Fig. 30 shows the control with the secondary antibody.

Riboprobe and the antibody also marked some VC traits (Fig. 3E,H).

\section{Discussion}

In the ovary, the transcription of both CiLgals immune-related genes and the protein production are a property of the FCs which envelope the follicles at stage II (vitellogenic) and, at a lesser extent, at the stage III follicles (post-vitellogenic). The CiLgals transcripts were never found in TCs and GVs in any observed oogenesis phase, meanwhile immunohistochemistry shows that both galectins are contained in ooplasmic vesicles and in the GV matrix (presumably associated to chromatin). The diverse intensity of the ISH and IH reactions observed in various histological sections, could be imputed to the follicle staging and phases of follicular morphogenesis. In this respect, the histological observations showed the FCs assemble with each other as an organized epithelial monolayer, and, at the vitellogenic stage, they display an elongated and fibroblast-like shape, whereas the post-vitellogenic FCs are more vacuolated, have a wider size and a more outstanding feature. The dynamic of the FC layer morphogenesis has been related to a nonproliferative process [62], so a putative effect of CiLgals as proliferation stimulus can be excluded, whereas a modulatory effect on FCs differentiation cannot be excluded [63]. Presumably due to the used histological method and/or the cutting level of the sections, we were not able to distinguish two FC layers (inner and outer) [49,52], moreover, these two layers have not been described by the previous electron microscopy study on C. intestinalis from the Mediterranean Sea [48].

The different intensity of CiLgals riboprobes and immunostaining marking in the FCs shown in various histological sections, could be dependent on the FC morphogenetic phases. In parallel, in follicles at II 

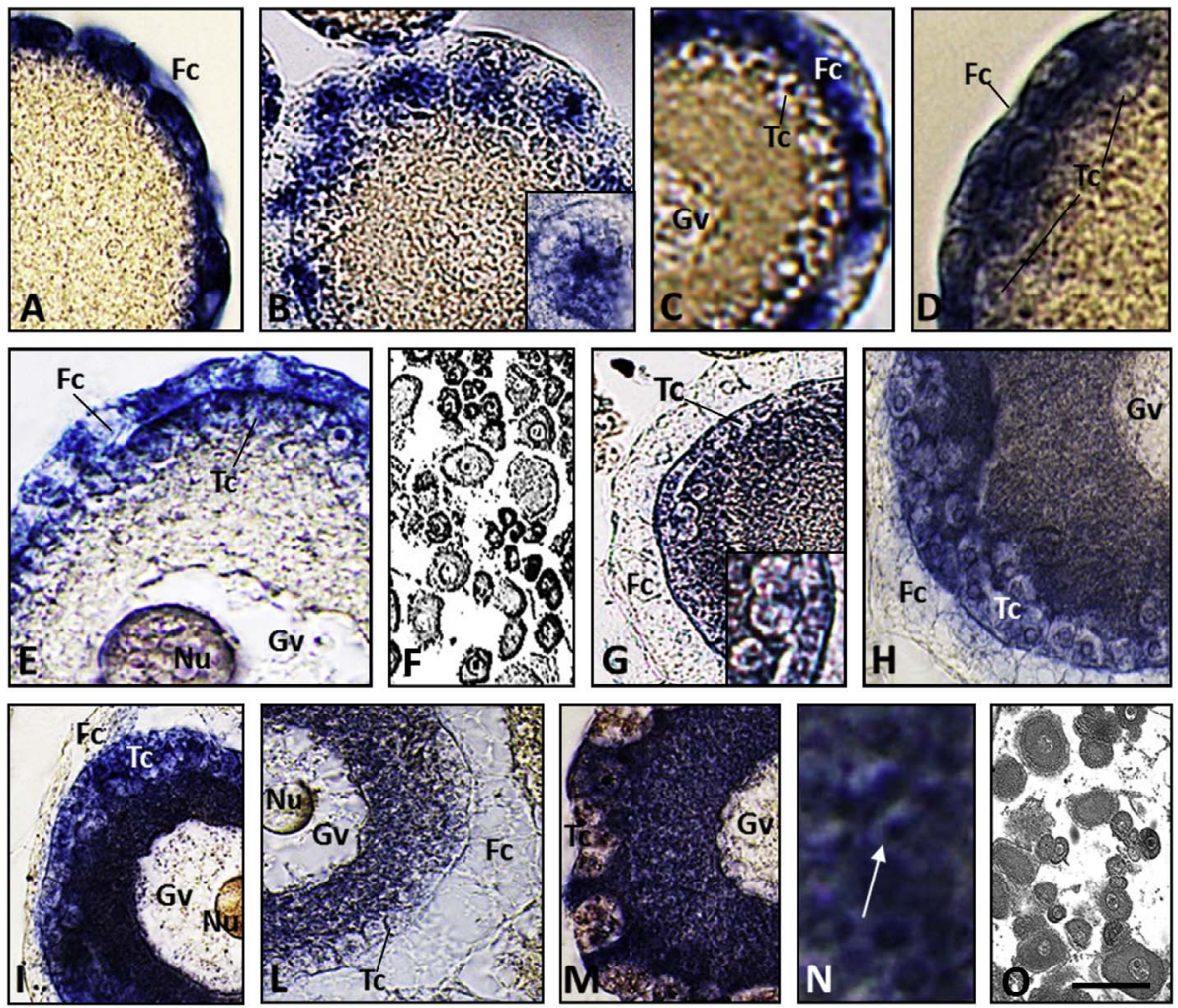

Fig. 3. Histological sections of Ciona intestinalis ovary. In situ hybridization (CinPO2 riboprobe) and immunohistochemistry (anti-CinPO2 primary antibody).

(A-E): In situ hybridization of II stage follicles. B: longitudinal view of a follicle in a section cut at the surface level, showing the riboprobe labeling of TCs (Tc); inset in B: magnification of an FC (Fc); C: labeled FCs (Fc) and unlabeled TCs (Tc) and GV (Gv) of a II stage follicle; D: the pervasive labeling mask the FC and TC layers; E: The labeling of FCs appears to be less intense, meanwhile TCs and VC (between FCs and TCs) are labeled. (F); ovary control section treated with the sense strand.

(G-N): Immunohistochemistry of II stage follicles marked by the antibody. (G-I): FCs (Fc) are not marked, whereas TCs (Tc) and ooplasm are marked; (H-M): the GV (Gv) and nucleolus (Nu) are unmarked; M: III stage follicle showing marked ooplasm and unmarked TCs which are full of granules; $\mathrm{N}$ : enlarged view showing vesicles containing a single $\mathrm{CinPO} 2$ granule with varying feature; $(\mathrm{O})$ : follicle section treated with the secondary antibody as a control. The bar, shown in the figure $\mathrm{O}$, also applies to all the others, and the relative measures are as follows: $180 \mu \mathrm{m}$ in $\mathrm{F}, \mathrm{O}$; $14 \mu \mathrm{m}$ in $\mathrm{A}, \mathrm{B}, \mathrm{C}, \mathrm{D}, \mathrm{E}, \mathrm{G}, \mathrm{H}, \mathrm{I}, \mathrm{L}, \mathrm{M} ; 3 \mu \mathrm{m}$ in $\mathrm{N}$. to III stage, the galectins enrich the ooplasm and appear to be transferred to the GV outer surface and into the nucleoplasm. In vitellogenic follicles, numerous small ooplasmic vesicles with immunoreactive content, together with a diffuse reaction product, are located in the ooplasm just below the TCs, and they can be so abundant to mask the TC layer features. Such a presumptive transfer from the FCs appears to be accomplished in the post-vitellogenic stage when both antibodies mark granular material abundant in GV (never labelled by the riboprobes) meanwhile the FCs are only feebly marked. Parallel to the abundant localization in the GV of post-vitellogenic follicles, both galectins appear to be mainly restricted in oocyte ooplasmic lobes localized between the TCs, indicating a phase in which the surface of FCs joins to the ooplasm. Previous TEM observations [48] have shown that, as vitellogenesis progresses, vesicular bodies populate the ooplasm that insinuated between the TCs forming lobes provided with microvilli which come in contact with the FCs.

Although, the present findings do not elucidate the CiLgals export mechanism, their cytolocalization may be indicative of a transcytosis process [64] possibly by direct translocation across the membranes and/or manufacturing of vesicles that become scattered in the ooplasm. In this respect, it is generally accepted that galectins are synthesized on free ribosomes and bypass the classical biosynthetic ER-Golgi pathway [25]. In addition, it is of interest to mention that the multifunctional mammalian galectin-3 has been detected in carrier vesicles [65] exported by membrane blebbing [66], and it reachs the nucleus; moreover, the polyvalent galectin-1 can be packed into vesicles that "bud off" at the plasma membrane [25].

The possibility exists that, in the GV of growing oocytes, the CiLgals may be associated to the nuclear matrix and/or chromatin presumably involved in modulation of the nuclear activity. In mammals, the galectin-1 and galectin-3 have been found to be associated with the nuclear matrix, and they form ribonucleoprotein complex also involved in splicesosome assembly, regulation of the RNA splicing and trafficking apparatus [67-69]. More pertinently, it has been shown that they are also expressed in male and female gonads [70,71].

In spite of the anti-CiLgals-a or CiLgals-b antibody specificty, formerly stated by ELISA and competitive ELISA [31], significant differences between CiLgals-a and CiLgals-b immunolocalizations were not found, while the transcription of both genes appear to be concurrent.

Since galectins are known to be involved in self-not self-recognition mechanisms [23], it is intriguing the immunoreactivity of the thin layer (VC) interposed between FCs and TCs. However, we do not know whether the CiLgals are components of the $\mathrm{VC}$ involved in the allorecognition mechanism responsible of the FC/VC-mediated self-incompatibility barrier established by the FCs against autologous sperms during the follicle maturation [50,51,72]. Our findings on the labeling of the VC layer may merely depend on the passive capture of galectins released from the FCs, as also shown by the labeling with $\mathrm{CinPO} 2$ riboprobe and antibody.

Although the CiLgals functions remain to be elucidated, the transcription upregulation and proteins production by inflammatory hemocytes, the constitutive transcription by the stomach epithelium [73] and the present findings on the ovary, suggest that the CiLgals could exert multiple roles. In this respect, some properties of the molecular structure can be recalled $[23,25,63]$, including the CRD ability to bind different glycan structures, the capability to form oligomers leading to increased affinity for various glycans that characterize the glycome of each cell type and development stages [74].

The second item discussed here concerns the CinPO2 gene expression. The phenoloxidase, that is an oxygenase as well as an oxidase, was found in bacterial biofilms [75], fungi, plants and animals, suggesting an early evolution [76]. Depending on species and evolutionary pressures the PO enzymes have been modified and show a low degree of sequence similarities. The PO pathway exerts multiple functions including wound healing and immune response, skin pigmentation, building of the exoskeleton and browning of fruits and vegetables.

In a previous paper, we reported the $\mathrm{CinPO} 2$ gene transcription by TCs that envelope the ovarian oocytes [8]. However, the former light microscopy observations did not clearly distinguish the FCs adherent to the oocyte surface, and they were retained TCs in which CinPO2 gene transcription and the enzyme localization occurred. The present 
observations display that the transcript is mainly found in FCs of vitellogenic follicles while the riboprobe also labeled the TCs in which the anti-CinPO2 antibody identified the protein, whereas the antibody never reacted with the FCs. These findings may be suggestive of an mRNA transcytosis from FCs into TCs also marking the interposed VC. It is known that exosomes containing mRNA can be delivered to another cell and it can be functional in this new location [77]. From the TCs, where the protein could be synthesized, the CinPO2 appears to be exocyted into the ooplasm through a vesicular mechanism. In this respect, some images show a lot of vesicles, containing immunoreactive material that concealed the usual morphology of TC layer. Previous fine structure observations have shown that [48], as vitellogenesis progresses, both TCs and FCs are contemporarily modified and these modifications correlate with the stage of development. In particular, the vitellogenic TCs are characterized by the protein synthesis machinery, then components of that machinery diminished indicating cell activity variations as shown by post-vitellogenic TCs in which dense granules and vacuoles occupy most of the cytoplasm $[48,62]$. As already seen for the CiLgals, PO-containing vesicles fill the cytoplasmic lobes interposed between the TCs typical of the post-vitellogenic stage.

Due to the wide range of PO activity and the various functions of the proPO activation pathway [76], we are not able to hypothesize the CinPO2 role during oogenesis, early embryogenesis and differentiation of mesenchymal cells in the larval tunic [8]. In the ovary, it is reasonable to relate the PO pathway with the increased expression and activity of chymotrypsin as challenged by tachykinin. Homologs of the mammalian ovary tachykinin (TK) and its receptor (TK-R) have been identified in Ciona ovary. The CiTK is an inducible factor for follicle growth from the vitellogenic stage to the post-vitellogenic stage; it induces the expression and enhances the activity of several proteases including the serine protease chymotrypsin, while the CiTK receptor is specifically expressed in TCs residing in vitellogenic oocytes [52]. These findings suggest that in Ciona ovary follicles the chymotrypsin could be involved in activation of the proenzyme proPO to active PO, as previously shown in the tunic inflammatory response [43].

In brief, during the follicle growth, the vitellogenic FCs appear to be engaged in CiLgals and CinPO2 genes transcription, whereas the possibility exists that the $\mathrm{CinPO} 2$ protein, as opposed to CiLgals, is synthesized by TCs as shown by a presumptive mRNA transcytosis process. Both CiLgals and CinPO2 are scattered in the oocyte ooplasm, but only the CiLgals reach the nucleus and are abundant in the nucleoplasm of post-vitellogenic GV.

Finally, the findings on the localization and gene transcription in various tissues of $C$. intestinalis, suggest the multifunctional role of the immune-related CiLgals and CinPO2 genes.

\section{Acknowledgements}

This work was supported by research grants from the Italian Ministry of Education (PRIN 2006 and 2010-2011 to N. Parrinello \& M. Cammarata Grant number 20044057000), co-funded by the University of Palermo. We thank M. Guarcello for collecting ascidians for maintenance of the aquaria.

\section{References}

[1] L. Zeng, B.J. Swalla, Molecular phylogeny of the protochordates: chordate evolution, Can. J. Zool. 83 (2005) 24-33.

[2] F. Delsuc, H. Brinkmann, D. Chourrout, H. Philippe, Tunicates and not cephalochordates are the closest living relatives of vertebrates, Nature 439 (2006) 965-968.

[3] B. Davidson, B.J. Swalla, A molecular analysis of ascidian metamorphosis reveals activation of an innate immune response, Development 129 (2002) 4739-4751.

[4] B. Roberts, B. Davidson, G. MacMaster, V. Lockhart, E. Ma, S.S. Wallace, B.J. Swalla, A complement response may activate metamorphosis in the ascidian Boltenia villosa, Dev. Genes Evol. 217 (2007) 449-458.

[5] K. Azumi, S.V. Sabau, M. Fujie, T. Usami, R. Koyanagi, T. Kawashima, S. Fujiwara, M. Ogasawara, M. Satake, M. Nonaka, H.-G. Wang, Y. Satou, N. Satoh, Gene expression profile during the life cycle of the urochordate Ciona intestinalis, Dev. Biol. 2007 (308) (2007) 572-582.

[6] T. Hibino, M. Nonaka, A novel third complement component C3 gene of Ciona intestinalis expressed in the endoderm at the early developmental stages, Inv Surv. J. 2013 (10) (2013) 29-37.

[7] N. Parrinello, A. Vizzini, G. Salerno, M.A. Sanfratello, M. Cammarata, V. Arizza, M. Vazzana, D. Parrinello, Inflamed adult pharynx tissues and swimming larva of Ciona intestinalis share CiTNF $\alpha$-producing cells, Cell Tissue Res. 341 (2010) 299-311.

[8] D. Parrinello, M.A. Sanfratello, A. Vizzini, M. Cammarata, The expression of an immune-related phenoloxidase gene is modulated in Ciona Intestinalis ovary, test cells, embryos and larva, J. Exp. Zool. (Mol Dev. Evol) 324B (2015) 141-151.

[9] I. Zucchetti, R. Marino, M.R. Pinto, J.D. Lambris, L. Du Pasquier, R. De Santis, ciCD94-1, an ascidian multipurpose C-type lectin-like receptor expressed in Ciona intestinalis hemocytes and larval neural structures, Differentiation 76 (2008) 267-282.

[10] G. Kumano, H. Nishida, Ascidian embryonic development: an emerging model system for the study of cell fate specification in chordates, Dev. Dyn. 236 (2007) 1732-1747.

[11] T. Matsuoka, T. Ikeda, K. Fujimaki, Y. Satou, Transcriptome dynamics in early embryos of the ascidian, Ciona Intestinalis, Dev. Biol. 384 (2013) 375-385.

[12] N. Satoh, The function and regulation of maternal transcripts, in: N. Satoh (Ed.), Developmental Genomics of Ascidians, Wiley Blackwell, Hoboken (NJ), 2014, pp. 41-51.

[13] H. Nishida, Specification of embryonic axis and mosaic development in ascidians, Dev. Dyn. 233 (2005) 1177-1193.

[14] K.S. Imai, K. Hino, K. Yagi, N. Satoh, Y. Satou, Gene expression profiles of transcription factors and signaling molecules in the ascidian embryo: towards a com prehensive understanding of gene networks, Development 131 (2004) 4047-4058.

[15] K. Hotta, H. Takahashi, A. Erives, M. Levine, N. Satoh, Temporal Expression Patterns of 39 Brachyury Downstream Genes Associated with Notochord Formation in the Ciona Intestinalis Embryo Dev Growth Differ vol. 41, (1999), pp. 657-664.

[16] L.-p. Liu, J.-h. Xiang, B. Dong, P. Natarajan, K.-j. Yu, N.-er. Cai, Ciona intestinalis as an emerging model organism: its regeneration under controlled conditions and methodology for egg dechorionation, J Zhejiang Univ Sci. B 7 (2006) 467-474.

[17] A.W. Reeves, R. Thayer, M. Veeman, Anterior-posterior regionalized gene expression in the Ciona notochord, Dev. Dyn. 243 (2014) 612-620.

[18] K.D. Smith, Genetic control of macromolecular synthesis during development of an ascidian - Ascidia nigra, J. Exp. Zool. 164 (1967) 393-405.

[19] Y. Sato, M. Morisawa, Loss of test cells leads to the formation of new tunic surface cells and abnormal metamorphosis in larvae of Ciona intestinalis (Chordata, ascidiacea), Dev. Genes Evol. 209 (1999) 592-600.

[20] S.M. Shimeld, M. Levin, Evidence for the regulation of left-right asymmetry in Ciona intestinalis by ion flux, Dev. Dyn. 235 (2006) 1543-1553.

[21] H. Thompson, S.M. Shimeld, Transmission and scanning electron microscopy of the accessory cells and chorion during development of Ciona intestinalis Type B embryos and the impact of their removal on cell morphology, Zool Sci. 32 (2015) 217-222.

[22] E.M. Rapoport, O.V. Kurmyshkina, N.V. Bovin, Mammalian galectins: structure, carbohydrate specificity, and functions, Biochem. (Moscow) 73 (2008) 393-405.

[23] G.R. Vasta, Galectins as pattern recognition receptors: structure, function and evolution, in: J.D. Lambris, G. Hajishengallis (Eds.), Current Topics in Innate Immunity II. Advances in Experimental Medicine and Biology, vol. 946, 2012, pp. 21-36 (XVIII).

[24] Klyosov AA. Galectins and their functions in plain language. In: Klyosov AA, Witczak ZJ, Platt D editors. Galectins. Hoboken (NJ): Wiley \& Sons p. 9-32.

[25] M. Viguier, T. Advedissian, D. Delacour, F. Poirier, F. Deshayes, Galectins in epithelial functions, Tissue Barriers 2 (2014) 1-9, http://dx.doi.org/10.4161/tisb. 29103 e29103.

[26] F. Liu, R. Patterson, J. Wang, Intracellular functions of galectins, Biochim. Biophys. Acta 1572 (2002) 263-273.

[27] I. Camby, M. Le Mercier, F. Lefranc, R. Kiss, Galectin-1: a small protein with major functions, Glycobiology 16 (2006) 137-157.

[28] Y. Yu, S. Yuan, Y. Yi, H. Huang, K. Feng, M. Pan, S. Huang, M. Dong, S. Chen, A. Xu, Molecular and biochemical characterization of galectin from amphioxus: primitive galectin of chordates participated in the infection processes, Glycobiology 17 (2007) 774-783.

[29] L. Ballarin, M. Cammarata, N. Franchi, N. Parrinello, Routes in innate immunity evolution: galectins and rhamnose-binding lectins in ascidians, in: Se-Kwon Kim (Ed.), Marine Proteins and Peptides: Biological Activities and Applications, John Wiley \& Sons, Ltd, 2013, pp. 185-205.

[30] D. Houzelstein, I.R. Goncalves, A.J. Fadden, S.S. Sidhu, D.N.W. Cooper, K. Drickamer, H. Leffler, F. Poirier, Phylogenetic analysis of the vertebrate galectin family, Mol. Biol. Evol. 21 (2004) 1177-1187.

[31] A. Vizzini, D. Parrinello, M.A. Sanfratello, G. Salerno, M. Cammarata, N. Parrinello, Inducible galectins are expressed in the inflamed pharynx of the ascidian Ciona intestinalis, Fish. Shellfish Immunol. 32 (2012) 101-109.

[35] H. Ahmed, S.J. Du, N. O'Leary, G.R. Vasta, Biochemical and molecular characterization of galectins from zebrafish (Danio rerio): notochord-specific expression of a prototype galectin during early embryogenesis, Glycobiology 14 (2004) 219-232.

[36] G.R. Vasta, H. Ahmed, S.-J. Du, D. Henrikson, Galectins in teleost fish: zebrafish (Danio rerio) as a model species to address their biological roles in development and innate immunity, Glycoconj J. 21 (2004) 503-521.

[37] A.J. Nappi, E. Ottaviani, Cytotoxicity and cytotoxic molecules in invertebrates, BioEssays 22 (2000) 469-480.

[38] M. Cammarata, V. Arizza, N. Parrinello, G. Candore, C. Caruso, Phenoloxidase-dependent cytotoxic mechanism in ascidian (Styela plicata) hemocytes active against 
erythrocytes and K562 tumor cells, Eur. J. Cell Biol. 74 (1997) 302-307.

[39] N. Parrinello, V. Arizza, C. Chinnici, D. Parrinello, M. Cammarata, Phenoloxidases in ascidian hemocytes: characterization of the prophenoloxidase activating system, Comp. Biochem. Physiol. B 1 (35) (2003) 583-591.

[40] A. Immesberger, T. Burmester, Putative phenoloxidases in the tunicate Ciona intestinalis and the origin of the arthropod hemocyanin superfamily, J. Comp. Physiol. B 174 (2004) 169-180.

[41] M. Cammarata, N. Parrinello, The ascidian prophenoloxidase activating system, Inv Surv. J. 6 (2009) 67-76.

[42] S. Giacomelli, D. Melillo, J.D. Lambris, M.R. Pinto, Immune competence of the Ciona intestinalis pharynx: complement system-mediated activity, Fish. Shellfish Immunol. 33 (2012) 946-952.

[43] M. Cammarata, V. Arizza, C. Cianciolo, D. Parrinello, M. Vazzana, A. Vizzini, G. Salemo, N. Parrinello, The prophenoloxidase system is activated during the tunic inflammatory reaction of Ciona intestinalis, Cell Tissue Res. 333 (2008) 481-492.

[44] D. Parrinello, M.A. Sanfratello, A. Vizzini, N. Parrinello, M. Cammarata, Ciona in testinalis galectin (CiLgals-a and CiLgals-b) genes are differentially expressed in endostyle zones and challenged by LPS, Fish. Shellfish Immunol. 42 (2015) 171-176.

[45] K. Kawamura, S. Tiozzo, L. Manni, T. Sunanaga, P. Burighel, A.W. De Tomaso, Germline cell formation and gonad regeneration in solitary and colonial ascidians, Dev. Dyn. 240 (2011) 299-308.

[46] T. Okada, M. Yamamoto, Identification of early oogenetic cells in the solitary ascidians, Ciona savignyi and Ciona intestinalis: an immunoelectron microscopic study, Dev. Growth Differ. 35 (1993) 495-506.

[47] R.R. Cowden, A comparative cytochemical study of oocyte growth and development in two species of ascidians, Acta Embryol. Morphol. Exp. 4 (1961) 123-141.

[48] V. Mancuso, An electron microscope study of the test cells and follicle cells of Ciona intestinalis during oogenesis, Acta Embryol. Morphol. Exp. 8 (1965) 239-266.

[49] C.C. Lambert, Ascidian follicle cells: multifunctional adjuncts to maturation and development, Dev. Growth Differ. 51 (2009) 677-686.

[50] F. Cotelli, F. Andronico, R. De Santis, A. Monroy, F. Rosati, Differentiation of the vitelline coat in the ascidian Ciona intestinalis: an ultrastructural study, Wilhelm Roux's Arch. 190 (1981) 252-258.

[51] R. De Santis, G. Jamunno, F. Rosati, A study of the chorion and the follicle cells in relation to sperm-egg interaction in the ascidian Ciona intestinalis, Dev. Biol. 74 (1980) 490-499.

[52] M. Aoyama, T. Kawada, M. Fujie, K. Hotta, T. Sakai, T. Sekiguchi, K. Oka, N. Satoh, H. Satake, A novel biological role of tachykinins as an up-regulator of oocyte growth: identification of an evolutionary origin of tachykininergic functions in the ovary of the ascidian, Ciona intestinalis, Endocrinology 149 (2008) 4346-4356.

[53] L. Caputi, N. Andreakis, F. Mastrototaro, P. Cirino, M. Vassillo, P. Sordino, Cryptic speciation in a model invertebrate chordate, Proc. Natl. Acad. Sci. 4 (2007) 9364-9369.

[54] M.L. Nydam, R.G. Harrison, Polymorphism and divergence within the ascidian genus Ciona, Mol. Phyl. Evol. 56 (2010) 718-726.

[55] R. Brunetti, C. Gissi, R. Pennati, L. Manni, Morphological evidence that the molecularly determined Ciona intestinalis type A and type B are different species: Ciona robusta and Ciona intestinalis, J. Zool. Syst. Evol. Res. (2015), http://dx.doi.org/10. 1111/jzs.12101.

[56] A. Sato, N. Satoh, J.D.D. Bishop, Field identification of 'types' A and B of the ascidian Ciona intestinalis in a region of sympatry, Mar. Biol. 159 (2012) 1611-1619.

[57] M.J. Kourakis, W.C. Smith, The natural history of model organisms. An organismal perspective on $C$. intestinalis development, origins and diversification, eLife 4 (2015) e06024, , http://dx.doi.org/10.7554/eLife.06024.

[58] K. Takamura, Y. Ueda, U. Irie, Y. Yamaguchi, Immunohistology with antibodies specific to test cells in the ascidian Ciona intestinalis suggests their role in larval tunic formation, Zool. Sci. 13 (1996) 241-251.

[59] Y. Sato, K. Terakado, M. Morisawa, Test cell migration and tunic formation during post-hatching development of the larva of the ascidian, Ciona intestinalis, Dev. Growth Differ. 39 (1997) 117-126.

[60] P.G. Plagemann, Epitope specificity of monoclonal antibodies to the N-protein of porcine reproductive and respiratory syndrome virus by ELISA with synthetic peptides, Vet. Immunol. Immunopathol. 1104 (2005) 50-68.

[61] J.D. Bancroft, M. Gamble, S. Kim, K.S. Suvarna, C. Layton, J.D. Bancroft (Eds.), Theory and Practice of Histological Techniques, seventh ed., Elsevier, Philadelphia, 2013Churchill Livingstone.

[62] Azzag K, Chelin Y, Rousset F, Le Goff E, Martinand-Mari C, Martinez A-M, Maurin B, Daujat-Chavanieu M, Godefroy N, Averseng J, Mangeat P, Baghdiguian S. The nonproliferative nature of ascidian folliculogenesis as a model of highly ordered cellular topology distinct from proliferative epithelia. PLoS One 10(5): e0126341 doi: 10.1371/journal.pone.012634;12015

[63] N.L. Perillo, M.E. Marcus, L.G. Baum, Galectins: versatile modulators of cell adhesion, cell proliferation, and cell death, J. Mol. Biol. 76 (1998) 402-412.

[64] P. Tuma, A.L. Hubbard, Transcytosis: crossing cellular barriers, Physiol. Rev. 83 (2003) 871-932.

[65] P. Lukyanov, V. Furtak, J. Ochieng, Galectin-3 interacts with membrane lipids and penetrates the lipid bilayer, Biochem. Biophys. Res. Commun. 338 (2005) 1031-1036.

[66] B. Mehul, R.C. Hughes, Plasma membrane targetting, vesicular budding and release of galectin 3 from the cytoplasm of mammalian cells during secretion, J. Cell Sci. 110 (1997) 1169-1178.

[67] S.F. Dagher, J.L. Wang, R.J. Patterson, Identification of galectin-3 as a factor in premRNA splicing, Proc. Natl. Acad. Sci. 92 (1995) 1213-1217.

[68] L. Wang, H. Inohara, K.J. Pienta, A. Raz, Galectin-3 is a nuclear matrix protein which binds RNA, Biochem. Biophys. Res. Commun. 217 (1995) 292-303.

[69] A. Vyakarnam, S.F. Dagher, J.L. Wang, R.J. Patterson, Evidence for a role of galectin-1 in pre-mRNA splicing, Mol. Cell Biol. 17 (1997) 4730-4737.

[70] M. Cho, R.D. Cummings, Galectin-1, a $\beta$-galactoside-binding lectin in Chinese hamster ovary cells. II. Localization and biosynthesis, J. Biol. Chem. 70 (1995) 5207-5212.

[71] M. Devouassoux-Shisheboran, C. Deschildre, C. Mauduit, G. Berger, F. MejeanLebreton, R. Bouvier, J.P. Droz, P. Fenichel, M. Benahmed, Expression of galectin-3 in gonads and gonadal sex cord stromal and germ cell tumors, Oncol. Rep. 16 (2006) 335-340.

[72] Y. Harada, H. Sawada, Allorecognition mechanisms during ascidian fertilization, Int. J. Dev. Biol. 52 (2008) 637-645.

[73] D. Parrinello, M.A. Sanfratello, A. Vizzini, L. Testasecca, N. Parrinello, M. Cammarata, The Ciona intestinalis immune-related galectin genes (CiLgals- $a$ and CiLgals- $b$ ) are expressed by the gastric epithelium, Fish. Shellfish Immunol. 62 (2017) 24-30.

[74] S. Di Lella, V. Sundblad, J.P. Cerliani, C.M. Guardia, D.A. Estrin, G.R. Vasta, G.A. Rabinovich, When galectins recognize glycans: from biochemistry to physiology and back again, Biochem. 50 (2011) 7842-7857.

[75] H. Peter, I. Ylla, C. Gudasz, A.M. Romaní, S. Sabater, L.J. Tranvik, Multifunctionality and diversity in bacterial biofilms, PLoS One 6 (8) (2011) e23225doi:10.13.

[76] H. Decker, N. Terwilliger, Cops and robbers: putative evolution of copper oxygenbinding proteins, J. Exp. Biol. 203 (2000) 1777-1782.

[77] H. Valadi, K. Ekstro"m, A. Bossios, M. Sjo“strand, J.J. Lee, J.O. Lo"tvall, Exosomemediated transfer of mRNAs and microRNAs is a novel mechanism of genetic exchange between cells, Nat. Cell Biol. 9 (2007) 654-659. 